\title{
Ultrastructure of in-vitro oocyte maturation in cattle
}

\author{
P. Hyttel, K. P. Xu*, S. Smith* and T. Greve* \\ Department of Anatomy and ${ }^{*}$ Institute for Animal Reproduction, Royal Veterinary and Agricultural \\ University, Bülowsvej 13, DK-1870 Frederiksberg C, Denmark
}

\begin{abstract}
Summary. Cumulus-oocyte complexes were collected from cows at an abattoir by aspiration from small $(1-6 \mathrm{~mm})$ antral follicles. After different periods of culture the complexes were processed for electron microscopy. Cumulus expansion occurred at $12-18 \mathrm{~h}$ of culture and concomitantly enlargement of cumulus cell projections in the perivitelline space was seen. At $48 \mathrm{~h}$ the innermost cumulus cells flattened and adhered tightly to the zona pellucida. In the oocyte the following changes occurred: at $0-3 \mathrm{~h}$ of culture the perivitelline space developed; at 3-12 $\mathrm{h}$ disconnection of the junctions between cumulus cell projections and the oolemma, and the concomitant breakdown of the nucleus was observed; at $12-18 \mathrm{~h}$ the mitochondria moved from a peripheral location to a more even spatial distribution and the Golgi complexes decreased in size; at $\sim 18 \mathrm{~h}$ the smooth endoplasmic reticulum formed large aggregates surrounded by mitochondria; at $18-21 \mathrm{~h}$ the first polar body was abstricted; at $24-40 \mathrm{~h}$ the cortical granules spread; at $30-40 \mathrm{~h}$ the polar body degenerated in some specimens; at $40-48 \mathrm{~h}$ the perivitelline space decreased in size; and at $48 \mathrm{~h}$ one oocyte was in the process of fragmentation. It is concluded that nuclear and cytoplasmic oocyte maturation is simulated in vitro. However, certain deviations were noticed compared to in-vivo maturation.
\end{abstract}

\section{Introduction}

Oocytes liberated from their follicles can spontaneously resume meiosis and complete at least nuclear maturation when cultured. This has been described in a number of species including cattle (Edwards, 1965; Hunter, Lawson \& Rowson, 1972; Shea, Latour, Bedirian \& Baker, 1976; Fukui \& Sakuma, 1980; for review see Fulka \& Motlik, 1980). Attempts to fertilize such in-vitro matured oocytes in vivo by transfer to inseminated oviducts have revealed that the developmental capacity of the resulting zygotes is low (cattle: Hunter et al., 1972; Trounson, Willadsen \& Rowson, 1977; Newcomb, Christie \& Rowson, 1978; sheep: Moor \& Trounson, 1977; Staigmiller \& Moor, 1984). Similar experiments in rabbits (Thibault \& Gérard, 1973; Motlik \& Fulka, 1974a) and pigs (Motlik $\&$ Fulka, 1974b) have demonstrated an inability to achieve male pronucleus formation possibly due to deviations in the course of cytoplasmic maturation.

In cattle, in-vitro fertilization of oocytes matured in vivo has given rise to live offspring (Brackett et al., 1982; Lambert et al., 1986) whereas in-vitro fertilization of oocytes matured in vitro has only resulted in development of early embryonic stages (Ball et al., 1983; Leibfried-Rutledge, Critser, Eyestone, Northey \& First, 1986), although one pregnancy has been obtained using oocytes matured in co-culture with granulosa cells (Critser, Leibfried-Rutledge, Eyestone, Northey \& First, 1986).

Ultrastructural investigations have revealed certain aspects of cytoplasmic oocyte maturation in vivo in unstimulated (Fleming \& Saacke, 1972; Kruip, Cran, van Beneden \& Dieleman, 1983) and gonadotrophin-stimulated cattle (Hyttel, Callesen \& Greve, 1986). However, only for human (Zamboni, Thompson \& Moore Smith, 1972; Sathananthan, 1985) and mouse (Merchant \& 
Chang, 1971) oocytes have the ultrastructural features of oocyte maturation in vitro been compared with those of in-vivo maturation, revealing only minor differences.

The practical use of in-vitro fertilization in cattle relies upon achieving proper oocyte maturation in vitro. The objectives of the present study were to provide an ultrastructural description of the nuclear and cytoplasmic changes taking place in the cumulus-oocyte complex during maturation in vitro.

\section{Materials and Methods}

Collection and culture of cumulus-oocyte complexes. Ovaries were obtained from cows within 30 min after slaughter at a local abattoir. Follicular contents were aspirated from visible antral follicles of about $1-6 \mathrm{~mm}$ in diameter. The aspirates were placed in a conical centrifuge tube containing $5 \mathrm{ml}$ Hepes-buffered (20 mM) Ham's F-10 medium (Flow Laboratories, Irvine, U.K.) supplemented with $20 \%$ heat-treated fetal calf serum (Flow Laboratories), $0.4 \mathrm{~mm}$-glutamine, 50 i.u. penicillin $/ \mathrm{ml}$ and $50 \mu \mathrm{g}$ streptomycin $/ \mathrm{ml}$ (collection medium). After $30-40 \mathrm{~min}$ the sedimented cumulus-oocyte complexes were aspirated and transferred to fresh collection medium, and within $2-3 \mathrm{~h}$ the cumulus-oocyte complexes were brought to the laboratory in a Thermos flask at $30-37^{\circ} \mathrm{C}$. Subsequently, they were washed in fresh collection medium and evaluated under a stereomicroscope. Only cumulus-oocyte complexes with a compact multilayered cumulus investment were included in the study (Fig. 1). The selected complexes were cultured in bicarbonate-buffered Ham's F-10 medium with the same supplementation as used in the collection medium plus 2 i.u. hCG/ml (Physex: Leo Pharmaceuticals, Ballerup, Denmark; $1 \mathrm{mg} \equiv 2252$ i.u.) and $1 \mu \mathrm{g}$ oestradiol benzoate/ml (Ovex: Leo Pharmaceuticals) (culture medium).

The start of culture was defined as the midpoint of the collection period. Culture was performed in 4-well multi-well dishes with 10-15 cumulus-oocyte complexes in each well containing $1 \mathrm{ml}$ culture medium at $38^{\circ} \mathrm{C}$ in a $5 \% \mathrm{CO}_{2}$ in humidified air. Complexes were fixed after culture for 3,6 , $9,12,18,21,24,30,40$ or $48 \mathrm{~h}$.

To establish a $0 \mathrm{~h}$ control group, cumulus-oocyte complexes were evaluated and fixed immediately after aspiration $(n=4)$ or aspirates were stored for $2-3 \mathrm{~h}$ without medium at $0^{\circ} \mathrm{C}$ until evaluation and fixation of the complexes $(n=7)$.
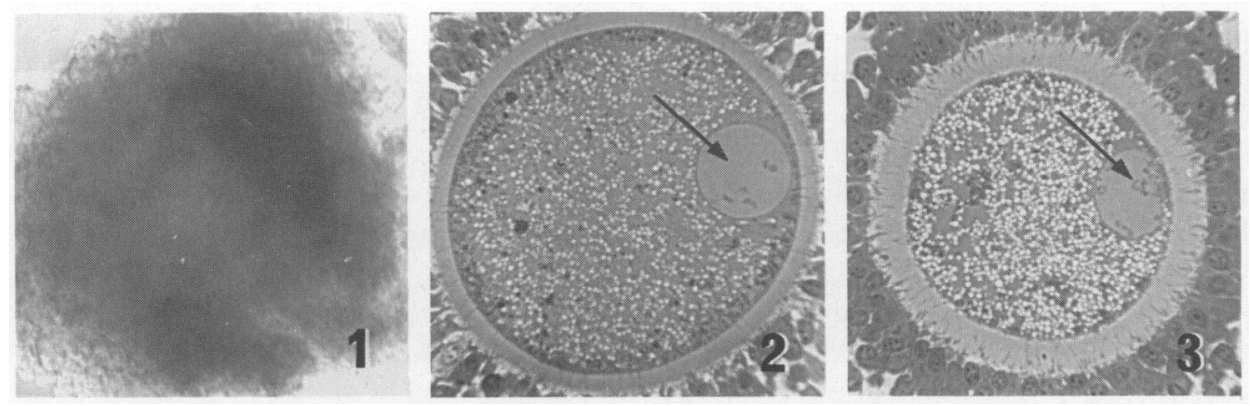

Fig. 1. Uncultured cumulus-oocyte complex after fixation in glutaraldehyde. Note the tight multilayered cumulus investment. $\times 150$.

Fig. 2. Control cumulus-oocyte complex of type I with a rounded oocyte nucleus (arrow). $\times 300$.

Fig. 3. Type I cumulus-oocyte complex cultured for $3 \mathrm{~h}$. Note the slightly flattened oocyte nucleus (arrow). $\times 300$. 
Tissue preparation. Cumulus-oocyte complexes ( $0 \mathrm{~h}$ control group, $n=11$; cultured, $n=43)$ were fixed in $3 \%$ glutaraldehyde in $0.1 \mathrm{M}$-phosphate buffer for $\mathrm{I} \mathrm{h}$ at $4^{\circ} \mathrm{C}$ and post-fixed in $1 \%$ $\mathrm{OsO}_{4}$ in. $0 \cdot 1 \mathrm{M}$-phosphate buffer for $1 \mathrm{~h}$ at $4^{\circ} \mathrm{C}$. Subsequently, they were washed in distilled water and block-stained with $0.5 \%$ uranyl acetate, dehydrated and embedded in Epon following standard procedures, and finally serially sectioned in semithin and ultrathin sections. Ultrathin sections were prepared when an oocyte nucleus, condensed chromatin configurations, or a polar body appeared in the semithin sections and/or at the equatorial plane of the oocyte. The semithin sections were stained with toluidine blue while the ultrathin sections were stained with uranyl acetate and lead citrate and examined on a JEM-1200 EX (Jeol, Tokyo, Japan).

\section{Results}

\section{Nuclear oocyte maturation}

Based upon structural features the aspirated cumulus-oocyte complexes were divided into the following stages of meiosis: oocytes with an intact rounded nucleus (type I) (Figs 2 \& 3), oocytes that had neither an intact rounded nucleus nor a polar body (type II) (Figs 4-6) and those that had a polar body (type III) (Figs 8 \& 9). These features were related to the culture time as indicated in Table 1. Oocyte nucleus breakdown occurred after 3 to about $12 \mathrm{~h}$ of culture and the first polar body was abstricted in the period from 18 to $21 \mathrm{~h}$. In some specimens at 40 and $48 \mathrm{~h}$, however, polar bodies were either not seen or they were lightly stained and considered to be degenerate (Fig. 9).

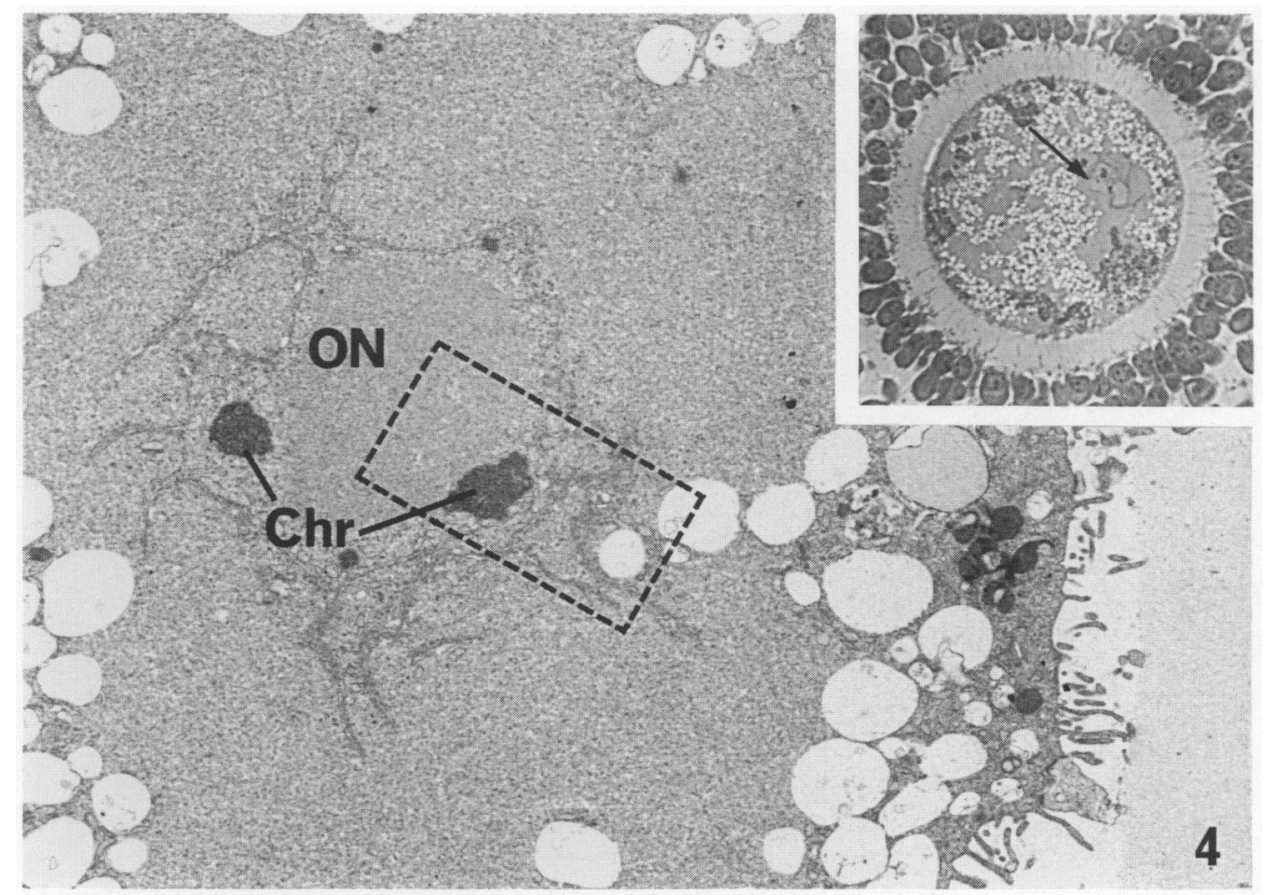

Fig. 4. Detail of a type II cumulus-oocyte complex in which the oocyte nucleus is in the process of breaking down after $12 \mathrm{~h}$ of culture. Note the convoluted oocyte nucleus (ON) in which condensed chromatin $(\mathrm{Chr})$ is seen. $\times 4400$. Inset showing the same cumulus-oocyte complex with the convoluted oocyte nucleus (arrow). $\times 300$. 


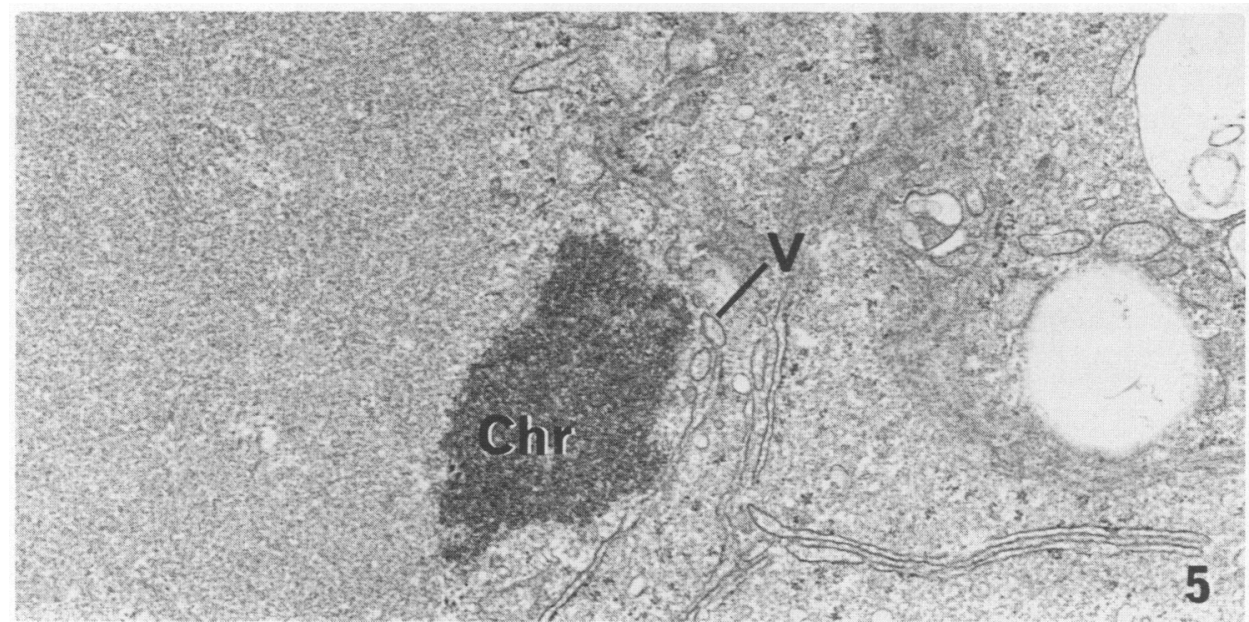

Fig. 5. Boxed area from Fig. 4 showing condensed chromatin (Chr) and disintegration of the nuclear envelope into vesicles (V). $\times 16800$.
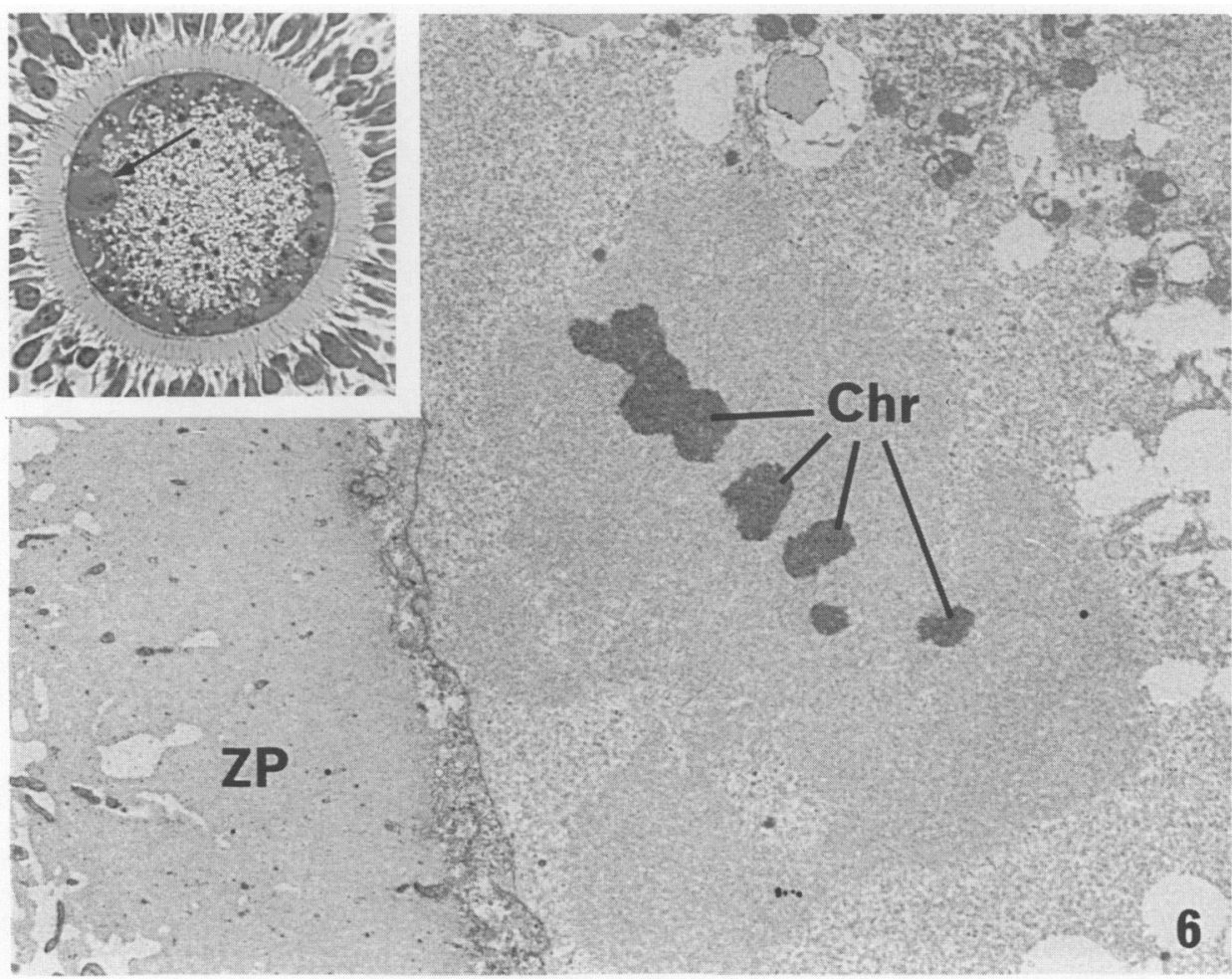

Fig. 6. Detail of a type II cumulus-oocyte complex cultured for $18 \mathrm{~h}$ showing the zona pellucida (ZP) and condensed chromatin configurations ( $\mathrm{Chr}$ ) located peripherally in the ooplasm in a densely packed area. $\times 5000$. Inset showing the same cumulus-oocyte complex. Note the expanded cumulus investment and the condensed chromatin configurations (arrow). $\times 300$. 


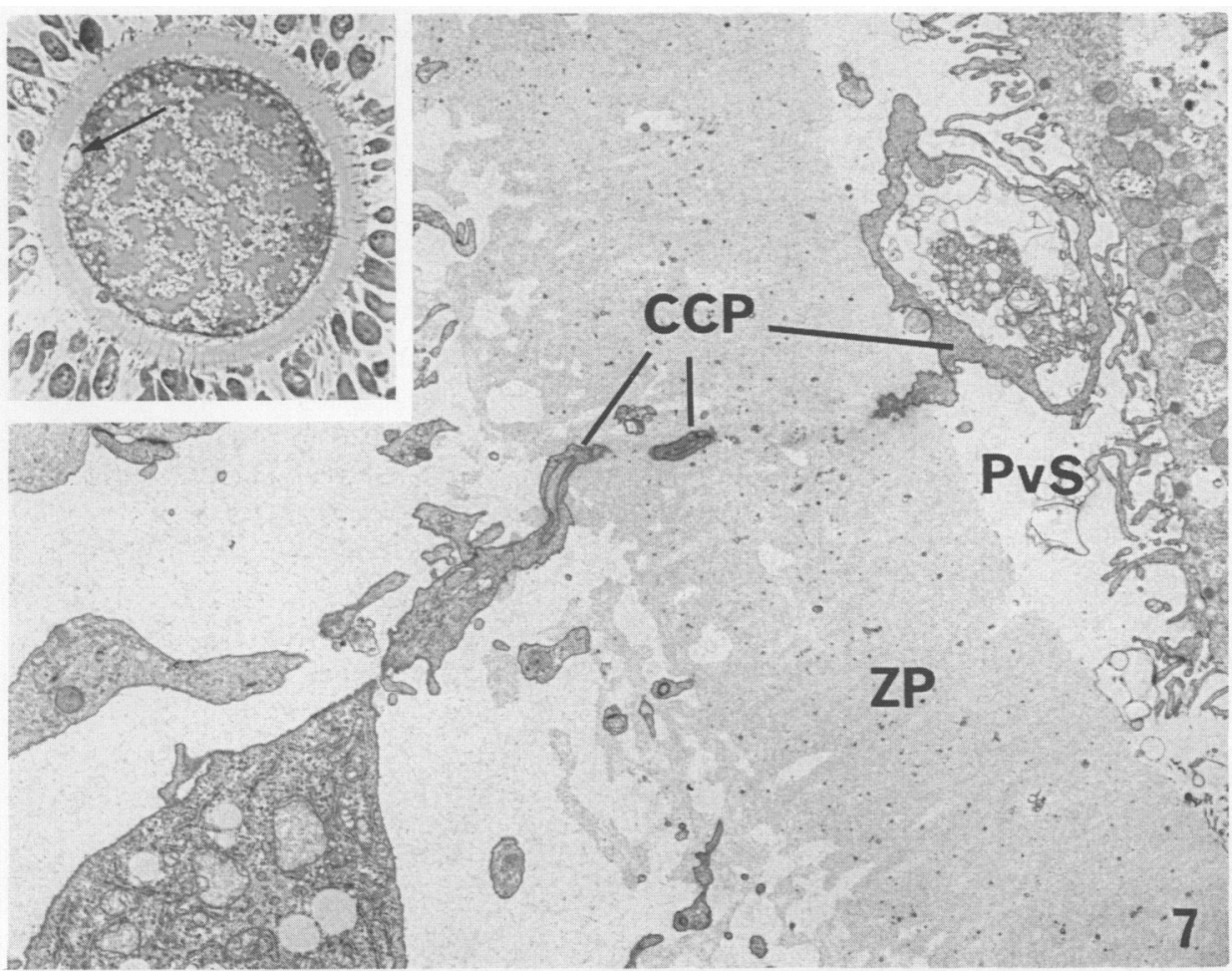

Fig. 7. Detail of a type III cumulus-oocyte complex cultured for $24 \mathrm{~h}$ showing the zona pellucida (ZP) which is traversed by a cumulus cell projection (CCP) with an enlargement in the perivitelline space $(\mathrm{PvS}) . \times 4800$. Inset showing the same cumulus-oocyte complex at a lower magnification at which the cumulus cell projection (arrow) exhibits similarities with a polar body. $\times 300$.

\section{Cumulus morphology}

All control cumulus-oocyte complexes had a multilayered cumulus investment in which the cells had well developed cisternae of rough endoplasmic reticulum and Golgi complexes. The cells adjacent to the zona pellucida had numerous projections which penetrated it and ended in invaginations of the oolemma. Junctions with a morphology similar to that of the zonula adhaerens and gap junctions were observed between these projections and the oolemma.

At $12 \mathrm{~h}$ of culture partial expansion of the cumulus cell investment was observed in some complexes, and at $18 \mathrm{~h}$ all complexes had completely expanded cumulus investments (Fig. 6). This cumulus morphology was maintained until $40 \mathrm{~h}$ of culture when decreased expansion was noticed in two complexes. At $48 \mathrm{~h}$ of culture the innermost cumulus cells flattened and adhered tightly to the zona pellucida (Fig. 11), and only one complex maintained partial expansion.

At $18 \mathrm{~h}$ of culture the oocyte of 2 complexes was degenerate although the expanded cumulus investment was unaltered. From $18 \mathrm{~h}$ of culture enlarged cumulus cell projections were frequently observed in the perivitelline space, some of a size similar to that of the first polar body (Fig. 7).

\section{Oocyte morphology and cytoplasmic maturation}

Control oocytes. The structure of the oocyte in the $0 \mathrm{~h}$ control complexes was similar to that described for oocytes aspirated before the occurrence of the LH peak in vivo (Hyttel et al., 
Table 1. Type of cumulus-oocyte complex relative to the period of culture

\begin{tabular}{cl}
\hline Culture period $(\mathrm{h})$ & $\begin{array}{l}\text { Type of } \\
\text { cumulus-oocyte complex }\end{array}$ \\
\hline Control complexes & I,I,I,I,I,I,I,I,I,I,I \\
3 & I,I,I \\
6 & I,II*, II*, II \\
9 & I,I,II* $^{*}$ \\
12 & I,II*, II*, II \\
18 & II, II, II, II, II, II, II, D,D \\
21 & III, III, III \\
24 & II, III, III, III, III \\
30 & III, III, III, III, III \\
40 & II, III, III $\dagger$ \\
48 & II, II, III $\dagger$, III $\ddagger$ \\
\hline
\end{tabular}

* Oocyte nucleus in the process of breaking down.

$\dagger$ Degenerated polar body.

$\ddagger$ Oocyte in the process of fragmentation.

D, Degenerate oocyte.
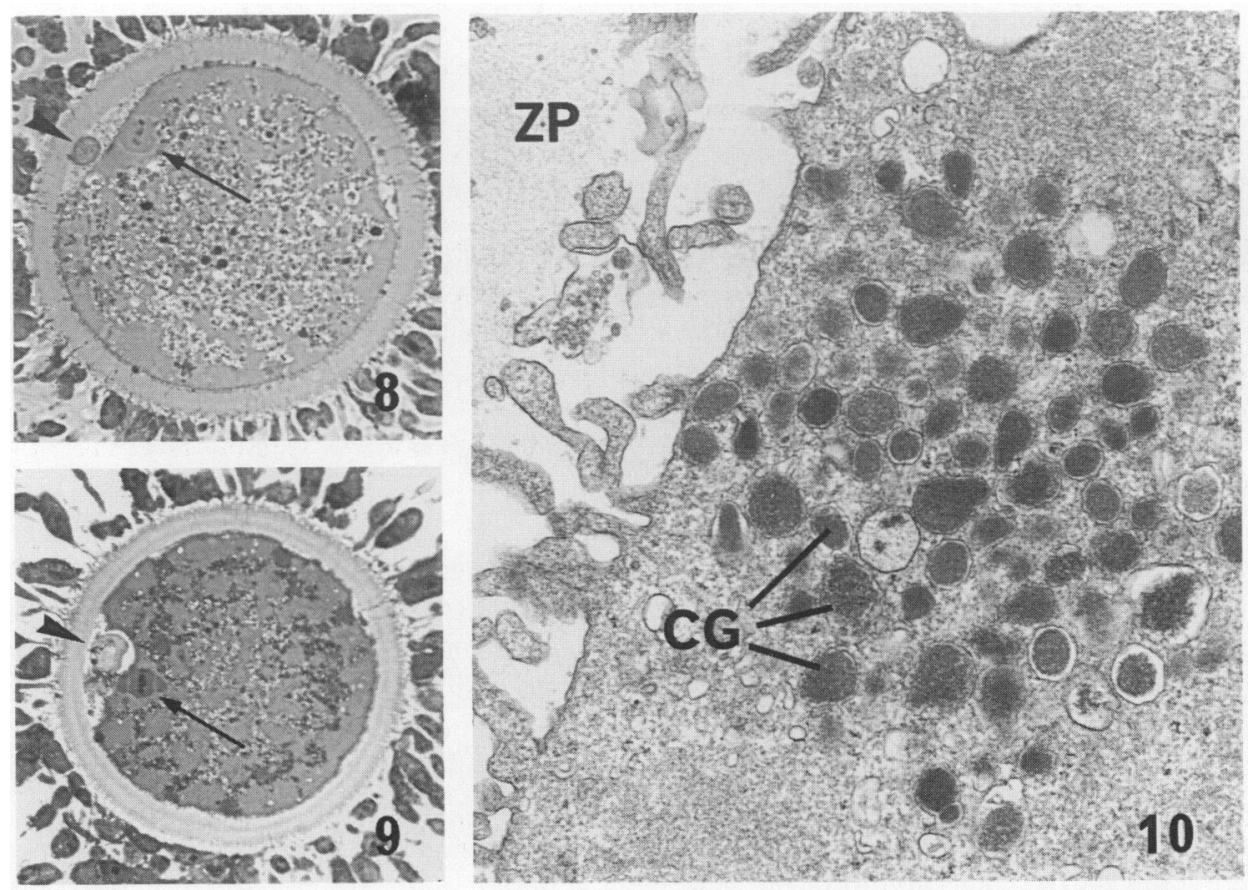

Fig. 8. Type III cumulus-oocyte complex cultured for $30 \mathrm{~h}$ showing the first polar body (arrowhead) and condensed chromatin configurations (arrow) located peripherally in the ooplasm in a densely packed area. $\times 300$.

Fig. 9. Type III cumulus-oocyte complex cultured for $40 \mathrm{~h}$ in which the first polar body (arrowhead) is degenerating. Again, condensed chromatin configurations are seen in the ooplasm (arrow). $\times 300$.

Fig. 10. Detail of a type III cumulus-oocyte complex cultured for $24 \mathrm{~h}$ showing the zona pellucida (ZP) and cortical granules (CG) still located in a big cluster. $\times 17000$. 


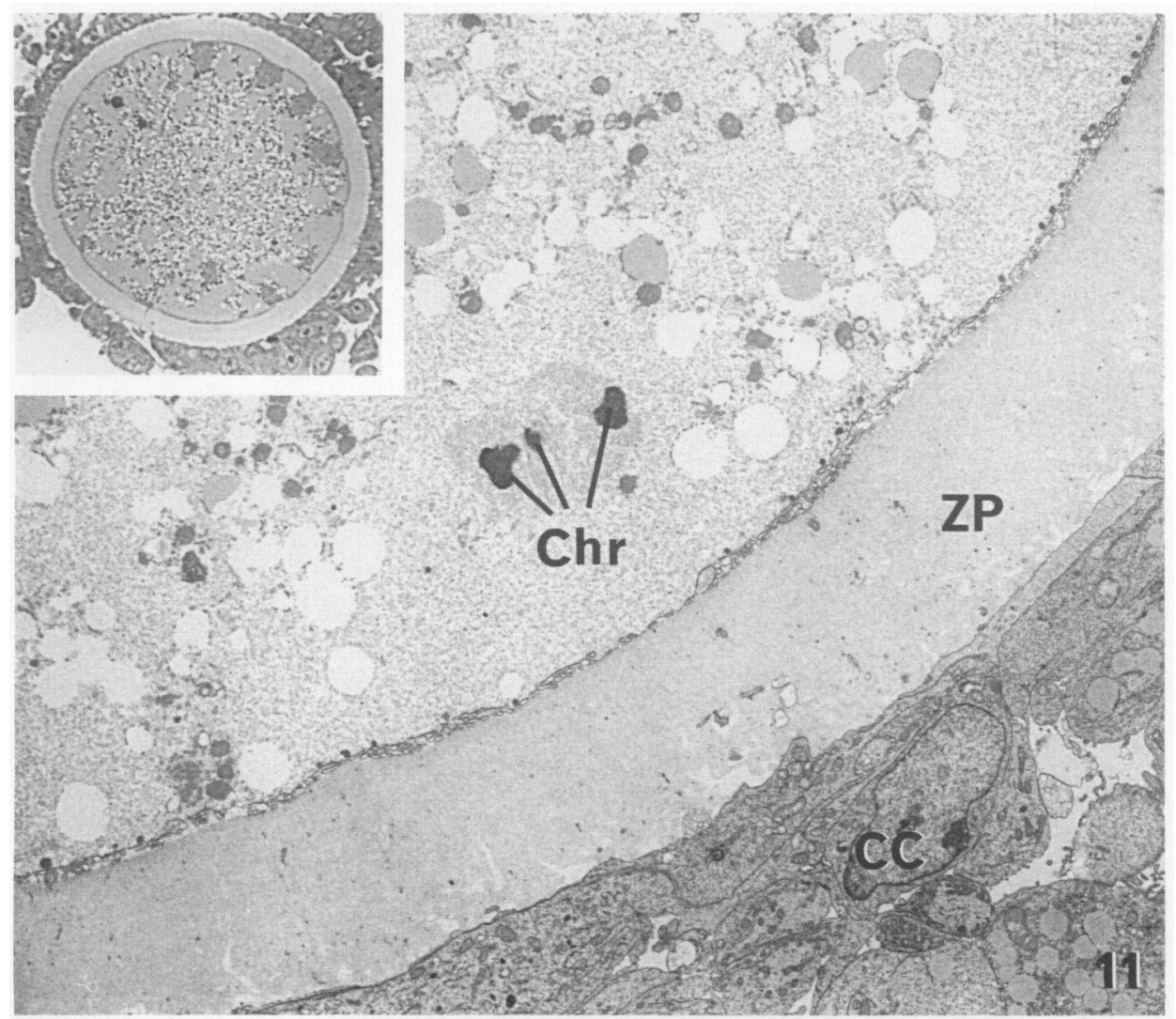

Fig. 11. Detail of a type III cumulus-oocyte complex cultured for $48 \mathrm{~h}$ showing cumulus cells (CC), zona pellucida (ZP) and in the ooplasm condensed chromatin configurations (Chr). $\times 3200$. Inset showing the same cumulus -oocyte complex at another section plane. Note the flat adhering cumulus investment. $\times 300$.

1986), i.e. absent or narrow perivitelline space, an eccentrically located nucleus, evenly distributed vesicles, peripheral mitochondrial clusters, well developed Golgi complexes and smooth endoplasmic reticulum (SER), large peripheral clusters of cortical granules and a close association between vesicles, lipid droplets and mitochondria throughout the SER.

Cultured oocytes. From 0 to $3 \mathrm{~h}$ of culture the perivitelline space developed and it enlarged until $9 \mathrm{~h}$ to a size which was maintained until $40 \mathrm{~h}$. During the initial enlargement of the perivitelline space the junctions between cumulus cell projections and the oolemma were maintained. At $48 \mathrm{~h}$ of culture all complexes had narrow perivitelline spaces (Fig. 11).

In 2 out of 3 oocytes the nucleus was flattened after $3 \mathrm{~h}$ of culture (Fig. 3). From 3 to about $12 \mathrm{~h}$ of culture the oocyte nucleus was broken down. An increasing undulation of the nuclear envelope was observed resulting in the formation of long slender projections in which the nuclear envelope doubled back on itself. Finally, the nuclear envelope was dissolved into vesicles (Figs $4 \& 5$ ). Concomitant with these events the chromatin condensed and an area of increased density appeared in the nucleus (Figs 4 \& 5). In some specimens, the chromatin was associated with the inner membrane of the nuclear envelope during this process. During the condensation of the chromatin, microtubules with a haphazard orientation appeared in the nucleus. After completion of the oocyte nucleus breakdown, condensed chromatin configurations were observed at peripheral sites in a 


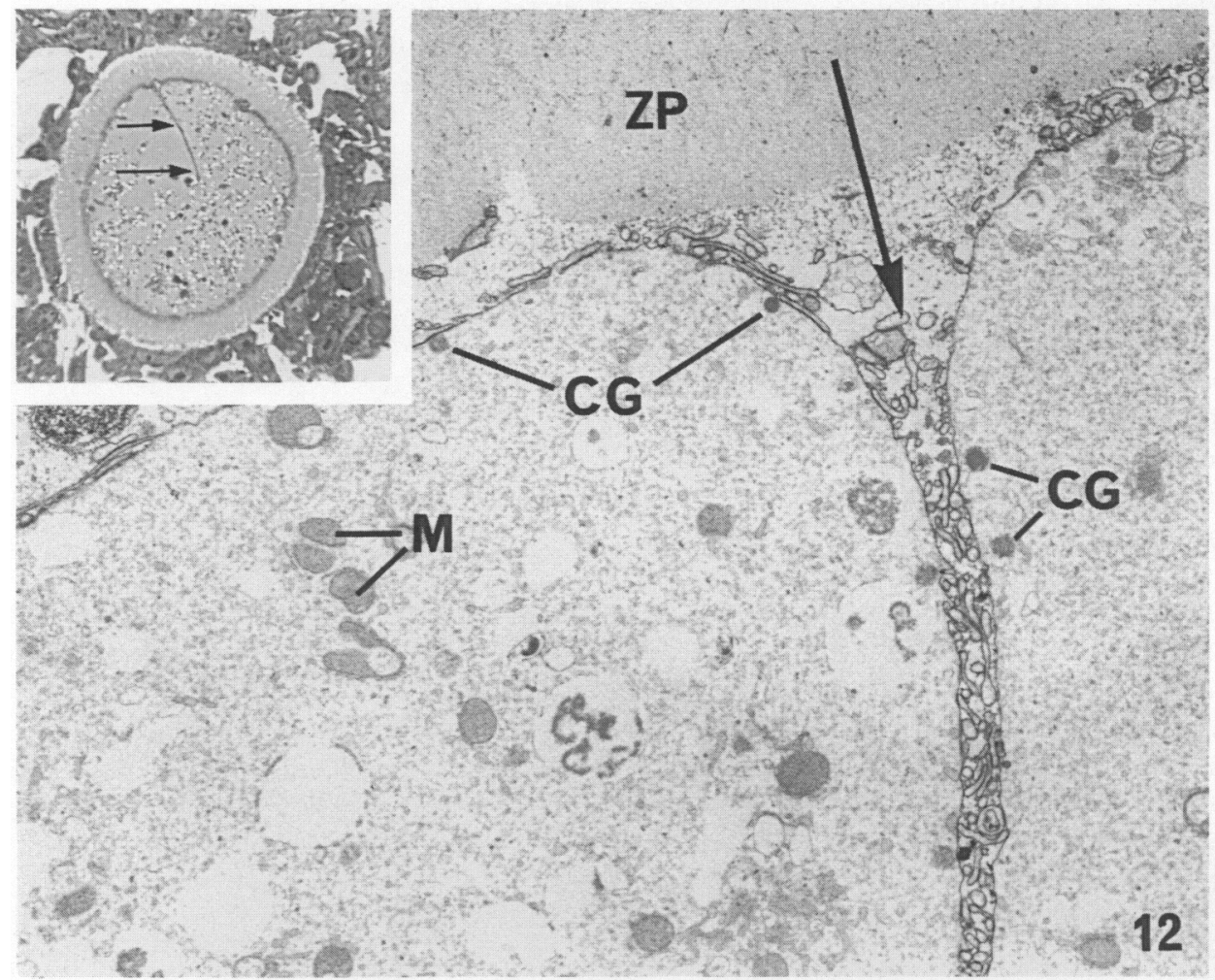

Fig. 12. Detail of a cumulus-oocyte complex cultured for $48 \mathrm{~h}$ showing the zona pellucida (ZP) and part of the oocyte in the process of fragmentation as indicated by the indentation of the oolemma (arrow). In the oocyte mitochondria (M) and cortical granules (CG) are seen. $\times 13800$. Inset showing the same cumulus-oocyte complex. Note the flat adhering cumulus investment and the indentation of the oolemma (arrows). $\times 300$.

densely packed area of the ooplasm (Fig. 6). At this stage the microtubules formed a well-organized spindle. Concomitant with the oocyte nucleus breakdown the junctions between cumulus cell projections and the oolemma were disrupted. All type I complexes displayed junctions, but in the type II complexes in which the oocyte nucleus was in the process of breaking down some of the junctions were disrupted. All other type II and all type III complexes showed a complete lack of junctions.

From 12 to $18 \mathrm{~h}$ of culture the mitochondria moved from their peripheral location in the ooplasm to an even spatial distribution, and the Golgi complexes decreased in size. At about $18 \mathrm{~h}$ of culture the vesicles tended towards a more central location and the SER either decreased in size or, characteristically, formed large aggregates surrounded by mitochondria. This aggregation was especially pronounced at $48 \mathrm{~h}$ of culture.

From 18 to $21 \mathrm{~h}$ of culture the first polar body was abstricted. In many specimens the polar body was surrounded by cytoplasmic droplets, some of which contained cortical granules. Again, condensed chromatin configurations were observed at peripheral sites in a densely packed area of the ooplasm (Figs 8 \& 9). At 24 and $30 \mathrm{~h}$ the cortical granules were dispersed from their location in large clusters to solitary positions forming a lining along the oolemma in 1 out of 5 and 2 out of 5 oocytes, respectively. In the remaining specimens the granules remained partly clustered (Fig. 10). At 40 and $48 \mathrm{~h}$ the cortical granules were dispersed in all occytes. 
At $48 \mathrm{~h}$ of culture one oocyte had a deep indentation from the oolemma and was in the process of fragmentation (Fig. 12). This oocyte had one set of condensed chromatin configurations peripherally in the ooplasm and still displayed a lining of cortical granules along the oolemma.

\section{Discussion}

The culture medium used in the present investigation has basically the same composition as that used by Newcomb et al. (1978) which, following in-vivo fertilization of in-vitro matured bovine oocytes, resulted in live offspring. Nuclear oocyte maturation apparently follows the same pattern in vivo and in vitro. In agreement with the findings of Sreenan (1970) and Motlik, Koefoed-Johnsen \& Fulka (1978) in-vitro oocyte nucleus breakdown occurred from 3 to about 12 h of culture. In vivo this feature is reported as taking place from 4 to $8 \mathrm{~h}$ and 6 to $14 \mathrm{~h}$ after the $\mathrm{LH}$ peak in unstimulated (Kruip et al., 1983) and gonadotrophin-stimulated (Callesen, Greve \& Hyttel, 1986; Hyttel et al., 1986) cattle, respectively. The abstriction of the first polar body occurred from 18 to $21 \mathrm{~h}$ in vitro, and is reported to take place about $20 \mathrm{~h}$ and $19 \mathrm{~h}$ after the LH peak in unstimulated (Kruip et al., 1983) and gonadotrophin-stimulated (Callesen et al., 1986; Hyttel et al., 1986) cattle, respectively.

The cytoplasmic oocyte maturation in vitro, as indicated by the ultrastructural changes, basically followed the same pattern as under in-vivo conditions and the biological implications of this sequence of events have been discussed in detail previously (Kruip et al., 1983; Hyttel et al., 1986). However, a certain variation and delay in the time of cortical granule spread was noticed in vitro compared to in vivo, in which the spread occurs around $19 \mathrm{~h}$ after the LH peak in unstimulated cattle (Kruip et al., 1983) and from 21 to $22 \mathrm{~h}$ after the peak in gonadotrophin-stimulated cattle (Hyttel et al., 1986). The cortical granule spread is regarded as being essential for the proper course of oocyte maturation (Sathananthan \& Trounson, 1982), and the release of the granules during gamete fusion is thought to act in the block against polyspermia (Austin, 1956; Szollosi, 1967). Deviations in the cortical granule spread might therefore decrease the likelihood of subsequent normal fertilization of the oocyte. However, contemporary in-vitro fertilization experiments using in-vitro matured oocytes clearly show that the frequency of polyspermia is low (K. P. Xu, unpublished data).

Major rearrangements of mitochondria and vesicles of the oocyte taking place between 12 and $18 \mathrm{~h}$ of culture are also reported as occurring in vivo around 19 and $15 \mathrm{~h}$ after the $\mathrm{LH}$ peak in unstimulated (Kruip et al., 1983) and gonadotrophin-stimulated (Hyttel et al., 1986) cattle, respectjvely. In both types of animals these rearrangements coincide with a shift from oestradiol dominance to progesterone dominance in the follicular fluid (Dieleman, Kruip, Fontijne, de Jong \& van der Weyden, 1983; Callesen et al., 1986). One could speculate that this shift might be the inducing factor of the organelle rearrangements in vivo and the existence of a similar steroidogenic shift in the present culture system due to cumulus cell activity cannot be excluded but needs further elucidation.

The clustering of the SER, described as one of the later characteristics of in-vitro oocyte maturation, is also observed in vivo (Hyttel et al., 1986). Kruip et al. (1983) suggested the existence of metabolic units in which lipid droplets, vesicles and mitochondria are combined through the SER. Thus, the clustering of the latter organelle may indicate a decrease in oocyte metabolism to a lower level which is maintained throughout the culture period.

From $18 \mathrm{~h}$ of culture enlarged cumulus cell projections were frequently observed in the perivitelline space, a finding which has also been reported in vivo, but at a much lower frequency (Hyttel et al., 1986). Light microscopically, the largest of these projections may be misinterpreted as polar bodies in unstained preparations and therefore erroneously suggest the completion of nuclear oocyte maturation. Correspondingly, K. P. Xu \& W. A. King (unpublished data) have observed metaphase $I$ in oocytes which appeared to have abstricted the first polar body.

At 40 and $48 \mathrm{~h}$ of culture the first polar body had degenerated and disappeared in some 
complexes and the perivitelline space decreased in size. Also, the degree of cumulus expansion decreased, resulting in the formation of a flat cell layer tightly adherent to the zona pellucida which probably deprives the oocyte of its ability to be fertilized as spermatozoa are phagocytosed by these cumulus cells (Pijnenborg, Gordts, Ongkowidjojo \& Brosens, 1985; cattle: P. Hyttel, unpublished data). Finally, one oocyte was in the process of fragmentation. Altogether, these changes suggest that long culture periods result in a certain overmaturation of the cumulus-oocyte complex, rendering it unsuitable for in-vitro fertilization purposes.

In conclusion, both nuclear oocyte maturation and the sequence of structural events which is part of the cytoplasmic oocyte maturation are simulated in vitro. However, certain deviations which may be causally involved in the low capability of fertilization and further embryonic development inherent to in-vitro matured oocytes were noticed.

We thank Miss Inger Madsen for skilful technical assistance. The work was supported by grant numbers 13-3641 and 5.10.17.06 from the Danish Agricultural and Veterinary Research Council and Leo Research Foundation.

\section{References}

Austin, C.R. (1956) Cortical granules in hamster eggs. Expl Cell Res. 10, 533-540.

Balt, G.D., Leibfried, M.L., Lenz, R.L., Ax, R.L., Bavister, B.D. \& First, N.L. (1983) Factors affecting successful in vitro fertilization of bovine follicular oocytes. Biol. Reprod. 28, 717-725.

Brackett, B.G., Bousquet, D., Boice M.L., Donawick, W.J., Evans, J.F. \& Dressel, M.A. (1982) Normal development following in vitro fertilization of bovine follicular oocytes. Biol. Reprod. 28, 717-725.

Callesen, H., Greve, T. \& Hyttel, P. (1986) Preovulatory endocrinology and oocyte maturation in superovulated cattle. Theriogenology 25, 71-86.

Critser, E.S., Leibfried-Rutledge, M.L., Eyestone, W.H., Northey, D.L. \& First, N.L. (1986) Acquisition of developmental competence during maturation in vitro. Theriogenology 25, 150.

Dieleman, S.J., Kruip, Th.A.M., Fontijne, P., de Jong, W.H.R. \& van der Weyden, G.C. (1983) Changes in oestradiol, progesterone and testosterone concentrations in follicular fluid and in the micromorphology of preovulatory bovine follicles relative to the peak of luteinizing hormone. J. Endocr. 97, 31-42.

Edwards, R.G. (1965) Maturation in vitro of mouse, sheep, cow, pig, rhesus monkey and human ovarian oocytes. Nature, Lond. 208, 349-351.

Fleming, W.N. \& Saacke, R.G. (1972) Fine structure of the bovine oocyte from the mature Graafian follicle. J. Reprod. Fert. 29, 203-213.

Fukui Y. \& Sakuma Y. (1980) Maturation of bovine oocytes cultured in vitro: Relation to ovarian activity, follicular size and the presence or absence of cumulus cells. Biol. Reprod. 22, 669-673.

Fulka, J. \& Motlik, J. (1980) 'In vitro' maturation. Proc. 9th Int. Congr. Anim. Reprod. \& A.I., Madrid 2, 55-62.

Hunter, R.H.F., Lawson, R.A.S. \& Rowson, L.E.A. (1972) Maturation, transplantation and fertilization of ovarian oocytes in cattle. J. Reprod. Fert. 30, $325-328$.
Hyttel, P., Callesen, H. \& Greve, T. (1986) Ultrastructural features of preovulatory oocyte maturation in superovulated cattle. J. Reprod. Fert. 76, 645-656.

Kruip, T.A.M., Cran, D.G., van Beneden, T.H. \& Dieleman, S.J. (1983) Structural changes in bovine oocytes during final maturation in vivo. Gamete Res. 8, $29-47$.

Lambert, R.D., Sirard, M.A., Bernard, C., Béland, R., Rioux, J.E., Leclerc, P., Ménard D.P. \& Bedoya, M. (1986) In vitro fertilization of bovine oocytes matured in vivo and collected at laparoscopy. Theriogenology 25, 117-133.

Leibfried-Rutledge, M.L., Critser, E.S., Eyestone, W.H., Northey, D.L. \& First, N.L. (1986) Developmental potential of bovine oocytes matured in vitro or in vivo. Theriogenology 25, 164 .

Merchant, H. \& Chang, M.C. (1971) An electron microscopic study of mouse eggs matured in vivo and in vitro. Anat. Rec. 171, 21-38.

Moor, R.M. \& Trounson, A.O. (1977) Hormonal and follicular factors affecting maturation of sheep oocytes in vitro and their subsequent developmental capacity. J. Reprod. Fert. 49, 101-109.

Motlik, J. \& Fulka, J. (1974a) Fertilization of pig follicular oocytes cultivated in vitro. J. Reprod. Fert. 36, 235-237.

Motlik, J. \& Fulka, J. (1974b) Fertilization and development in vivo of rabbit oocytes cultivated in vitro. $J$. Reprod. Fert. 40, 183-186.

Motlik, J., Koefoed-Johnsen, H.H. \& Fulka, J. (1978) Breakdown of the germinal vesicle in bovine oocytes cultivated in vitro. J. exp. Zool. 205, 377-384.

Newcomb, R., Christie, W.B. \& Rowson, L.E.A. (1978) Birth of calves after in vivo fertilization of oocytes removed from follicles and matured in vitro. Vet. Rec. 102, 461-462.

Pijnenborg, R., Gordts, S., Ongkowidjojo, R. \& Brosens, I. (1985) Sperm phagocytosis by corona cells in a human in vitro fertilization system. Ann. N.Y. Acad. Sci. 442, 310-317. 
Sathananthan, A.H. (1985) Maturation of the human oocyte in vitro: nuclear events during meiosis (An ultrastructural study). Gamete Res. 12, 237-254.

Sathananthan, A.H. \& Trounson, A.O. (1982) Ultrastructural observations on cortical granules in human follicular oocytes cultured in vitro. Gamete Res. 5, 191-198.

Shea, B.F., Latour, J.P.A., Bedirian, K.N. \& Baker, R.D. (1976) Maturation in vitro and subsequent penetrability of bovine follicular oocytes. J. Anim. Sci. 43, 809-875.

Sreenan, J. (1970) In vitro maturation and attempted fertilization of cattle follicular oocytes. J. agric. Sci., Camb. 75, 393-396.

Staigmiller, R.B. \& Moor, R.M. (1984) Effect of follicle cells on the maturation and developmental competence of ovine oocytes matured outside the follicle. Gamete Res. 9, 221-229.
Szollosi, D. (1967) Development of cortical granules and the cortical reaction in rat and hamster eggs. Anat. Rec. 159, 431-446.

Thibault, C. \& Gérard, M. (1973) Cytoplasmic and nuclear maturation of rabbit oocytes in vitro. Annls Biol. anim. Biochim. Biophys. 13, 145-156.

Trounson, A.O., Willadsen, S.M. \& Rowson, L.E.A. (1977) Fertilization and development capability of bovine follicular oocytes matured in vitro and in vivo and transferred to the oviducts of rabbits and cows. J. Reprod. Fert. 51, 321-327.

Zamboni, L., Thompson, R.S. \& Moore Smith, D. (1972) Fine morphology of human oocyte maturation in vitro. Biol. Reprod. 7, 425-457.

Received 1 April 1986 